\title{
Biofilm mediated synergistic degradation of hexadecane by a naturally formed community comprising Aspergillus flavus complex and Bacillus cereus group
}

Madushika Perera', Dilrukshi Wijayarathna², Sulochana Wijesundera', Manoj Chinthaka ${ }^{3}$, Gamini Seneviratne ${ }^{4}$ and Sharmila Jayasena ${ }^{1 *}$ (1)

\begin{abstract}
Background: The hydrophobic nature of hydrocarbons make them less bioavailable to microbes, generally leading to low efficiency in biodegradation. Current bioremediation strategies for hydrocarbon contamination, uses induced mixed microbial cultures. This in-vitro study demonstrates the utilization of naturally occurring communities in suitable habitats for achieving highly efficient, synergistic degradation of hydrocarbons in a simple community structure without additives.

Methods: Enrichment media supplemented with 1\% (7652.53 mg/L) hexadecane (HXD) as the sole carbon source were inoculated with samples of soil with waste polythene, collected from a municipal landfill in order to isolate microbial communities. Gas Chromatography-Mass Spectrometry (GC-MS) analysis was performed on HXD grown co-cultures and individual counterparts after 14 days incubation and percentage degradation was calculated. Microbes were identified using $16 \mathrm{~S}$ rRNA gene and Internal Transcribed Spacer region sequencing. Biofilm formation was confirmed through scanning electron microscopy, in the most efficient community.

Results: Three mixed communities (C1, C2 and C3) that demonstrated efficient visual disintegration of the HXD layer in the static liquid cultures were isolated. The $\mathrm{C} 1$ community showed the highest activity, degrading > 99\% HXD within 14 days. C1 comprised of a single fungus and a bacterium and they were identified as a Bacillus sp. MM1 and an Apsergillus sp. MM1. The co-culture and individual counterparts of the $\mathrm{C} 1$ community were assayed for HXD degradation by GC-MS. Degradation by the fungal and bacterial monocultures were $52.92 \pm 8.81 \%$ and $9.62 \pm 0.71 \%$ respectively, compared to $99.42 \pm 0.38 \%$ by the co-culture in 14 days. This proved the synergistic behavior of the community. Further, this community demonstrated the formation of a biofilm in oil-water interface in the liquid medium. This was evidenced from scanning electron microscopy (SEM) showing the Bacillus cells attached on to Aspergillus mycelia.

Conclusions: This study demonstrates the utilization of naturally formed fungal-bacterial communities for enhanced biodegradation of hydrocarbons such as hexadecane and reports for the first time, synergistic degradation of hexadecane through biofilm formation, by a community comprising of Bacillus cereus group and Aspergillus flavus complex.
\end{abstract}

Keywords: Aspergillus, Bacillus, Biofilm, Synergism, Hydrocarbon, Hexadecane, Biodegradation, Microbial community

\footnotetext{
* Correspondence: sharmila@bmb.cmb.ac.lk

${ }^{1}$ Department of Biochemistry and Molecular Biology, Faculty of Medicine,

University of Colombo, Colombo 08, Sri Lanka

Full list of author information is available at the end of the article
}

(c) The Author(s). 2019 Open Access This article is distributed under the terms of the Creative Commons Attribution 4.0 International License (http://creativecommons.org/licenses/by/4.0/), which permits unrestricted use, distribution, and reproduction in any medium, provided you give appropriate credit to the original author(s) and the source, provide a link to the Creative Commons license, and indicate if changes were made. The Creative Commons Public Domain Dedication waiver (http://creativecommons.org/publicdomain/zero/1.0/) applies to the data made available in this article, unless otherwise stated. 


\section{Background}

Microbial community mediated degradation of environmental pollutants is a promising application over exploiting the genetic potential of single microbes to clean up contaminants. Although this single microbe technology has been exploited in the past for its potential for bioremediation, there are limitations pertaining to the bioavailability and recalcitrant nature of contaminants.

Hydrocarbon contamination in aquatic as well as in terrestrial habitats are one of the major concerns worldwide. Aliphatic and aromatic fractions of hydrocarbons are both found in the contaminated sites. Single organisms of various microbial genera have been reported [1] to degrade these hydrocarbons. However, the hydrophobic nature of hydrocarbons makes it less bioavailable to microbes, hence they persist in the environment for extended periods of time. These complex organic contaminants are therefore not easily mineralized as no organism can alone remove them.

Single/pure cultures of microbes in planktonic mode or as biofilms have been of great interest over the last few decades, with regard to biodegradation of contaminants $[2,3]$. In laboratory conditions, pure cultures obtained from environmental samples are tested for contaminant degradation considering only abiotic factors, without due consideration of the nature of its natural habitat; whether it is present as a single organism, as planktonic cells, or as biofilms or it is adapted to a community mode of mixed organisms. Therefore, exploitation of an organism's full potential in removal of contaminants by manipulating its environment requires that its community behavior is taken in to consideration, even in the laboratory applications.

In nature, microbes interact with all biotic and abiotic factors and maintain its persistence through balancing the synergistic and antagonistic effects. Synergism allows microbes to thrive in various habitats through adaptation. A community of microbes consisting of multiple species contains an increased repertoire of genes and metabolic capabilities compared to monocultures. Thus, if one organism alone could not achieve the complete utilization of a particular substrate, it can harness the potential of other members of the community in order to maximize the output of the process. This is described as the division of labor across organisms in natural communities [4].

Fungal-bacterial interactions address both bioavailability and bioaccessability which otherwise hinder the initial oxidation of contaminants in the process of mineralization. Bacterial biofilms on fungal surfaces is a special form of biofilms where bacterial cells attach to fungal hyphae which is a biotic surface, rather than attaching on to abiotic surfaces [5]. Fungal hyphae are not merely a surface to support the attachment but play multiple roles. They provide a source of nutrients for bacteria, enable bacteria to "travel" with hyphae in the available medium in search of nutrients [6] providing bioaccessability to bacteria and increase acquisition of nutrients by competition etc. Soil associated penanthrene has been shown to be degraded by motile Pseudomonas putida PpG7 only in the presence of Pythium ultimum fungal mycelia [7].

Various chemical stimuli released by fungi attract bacteria by chemotactic response. Bacillus subtilis has been reported to migrate through soil toward fungal spores as a chemotactic response, to exudates released from them [8]. Expression of specific genes upon contact with fungal cells $[9,10]$ is another advantage of fungal - bacterial biofilms. Several $P$. putida genes (an uncharacterized transcription factor, an $\mathrm{ABC}$ transporter, and a porin) have been reported to be induced during growth on the surface of the fungus Phytophthora parasitica [11] P. fluorescens has been shown to induce its trehalose utilization genes when exposed to fungal culture supernatant [12]. Trehalose is a sugar commonly found in fungi which acts as a chemo attractant [13]. In favor of biofilm formation on fungal hyphae, bacteria provide extracellular polymeric substances (EPS), facilitating the attachment of cells [14]. Bacterial motility greatly influences them to reach surfaces suitable for formation of biofilm and flagella help to adhere on to the surface $[15,16]$. $B$. cereus and $B$. thuringiensis adhere on to biotic surfaces through their flagella [17].

The aim of this study was to investigate the interaction between Bacillus sp. and Aspergillus sp. growing in HXD as the sole carbon source for possible synergistic activity and to examine the mode of interaction of the two organisms in the co-culture.

\section{Methods}

\section{Collection of samples}

Samples of waste polythene (with attached soil) were collected from a municipal landfill (Meethotamulla, Kolonnawa) in Colombo district, Sri Lanka. Samples were collected (in to sterile containers) at a depth of $1-6 \mathrm{~cm}$ from soil surface, in order to acquire an aerobic microbial population [18]. The temperature of the collection spot was $42^{\circ} \mathrm{C}$. Sample $\mathrm{pH}$ was 9.5 . Collected samples were stored at $4{ }^{\circ} \mathrm{C}$.

\section{Culture conditions}

Nutrient broth (NB) or nutrient agar (NA) and Sabouraud dextrose broth (SDB) or Sabouraud dextrose agar (SDA) media (Hardy Diagnostics) were used to isolate and maintain bacterial and fungal cultures respectively. Bushnell and Haas (BH) medium [19], $\mathrm{MgSO}_{4} 0.2 \mathrm{~g} / \mathrm{L}, \mathrm{CaCl}_{2} 0.02 \mathrm{~g} / \mathrm{L}$, $\mathrm{KH}_{2} \mathrm{PO}_{4} \quad 1.0 \mathrm{~g} / \mathrm{L}, \quad \mathrm{K}_{2} \mathrm{HPO}_{4} 1.0 \mathrm{~g} / \mathrm{L}, \quad\left(\mathrm{NH}_{4}\right)_{2} \mathrm{SO}_{4} 1.0 \mathrm{~g} / \mathrm{L}$, $\mathrm{FeCl}_{3} 0.05 \mathrm{~g} / \mathrm{L}, 6.8 \mathrm{pH}$, was used in assays which were conducted to measure the ability of microbes to utilize a given source of carbon and energy. Filter sterilized $(0.22 \mu \mathrm{m}$ 
pore size) n-hexadecane $\left(\mathrm{C}_{16} \mathrm{H}_{34}\right)$ (HXD) (Sigma-Aldrich), crude oil (obtained from Ceylon Petroleum Corporation (CEYPETCO) refinery), diesel and petrol (obtained from a CEYPETCO filling station - Colombo, Sri Lanka) were individually used as the sole source of carbon and energy in $\mathrm{BH}$ medium at a concentration of $1 \%(\mathrm{v} / \mathrm{v})$. The incubation temperature was set at $40^{\circ} \mathrm{C}$. Experiments were carried out under aerobic conditions (without agitation to enhance the microbial growth in the form of a biofilm) unless otherwise specified. All assays were conducted in triplicate and with a negative control (under same conditions, without microbial inoculum).

\section{Culture enrichment and isolation of microbes}

NB $(100 \mathrm{~mL})$ was inoculated with $1 \mathrm{~g}$ of each of the collected samples and incubated for $16 \mathrm{~h}$ on a rotary shaker (180 rpm). Culture enrichment was carried out in BH medium $(100 \mathrm{~mL})$ supplemented with $1 \%$ HXD. Enrichment medium was inoculated with $1 \%$ of the NB culture and incubated until microbial growth was observed (approximately three weeks). The turbid broth was serially diluted and spread on NA and incubated for $16 \mathrm{~h}$. Well separated single colonies were streaked on NA to obtain pure bacterial cultures.

\section{Screening and selection of isolates for further studies}

The bacterial isolates obtained above were grown on $\mathrm{BH}$ medium supplemented with $1 \%$ HXD individually and re-screened for HXD degradation, based on the visual disintegration of the HXD layer with oil droplets on the medium.

\section{Isolation of community counterparts}

Naturally formed mixed communities $(\mathrm{C} 1, \mathrm{C} 2, \mathrm{C} 3)$ that appeared during screening were grown on both NA to (promote bacterial growth) and SDA (to promote fungal growth) in order to identify the participating bacteria and fungi in each community. Bacteria were purified as mentioned above and fungi were purified using single spore isolation technique [20]. Finally they were preserved in glycerol and stored in $-80^{\circ} \mathrm{C}$ [21].

\section{Identification of microbes in the community C1}

Identification of bacteria was performed by microscopic, biochemical and molecular techniques. Gram's staining and biochemical tests were performed according to the Bergey's Manual of Systematic Bacteriology [22]. For molecular identification, genomic DNA was extracted using Wizard Genomic DNA Purification Kit (Promega) according to the manufacturer's instructions. The $16 \mathrm{~s}$ rRNA gene was amplified by polymerase chain reaction (PCR) with universal primers; Primer forward (27F); 5' AGAGTTTGATCMTGGCTCAG 3' and primer reverse; (1492R) 5' GTA TTA CCG CGG CTGCTGG 3' [23].
The following thermal profile was used; initial denaturation at $95^{\circ} \mathrm{C}$ for $5 \mathrm{~min}, 30$ cycles of denaturation at $95^{\circ}$ $\mathrm{C}$ for $30 \mathrm{~s}$, annealing at $55^{\circ} \mathrm{C}$ for $30 \mathrm{~s}$ and extension at $72{ }^{\circ} \mathrm{C}$ for $90 \mathrm{~s}$ and a final extension at $72{ }^{\circ} \mathrm{C}$ for $10 \mathrm{~min}$. The amplified gene was sequenced (Macrogen Co. South Korea (ABI PRISM 3730XL Analyzer-96 capillary type). The obtained sequence was analyzed by Basic Local Alignment Search Tool (BLAST), http://www.ncbi.nlm. nih.gov/blast, National Center for Biotechnology Information (NCBI), to identify the organism.

Fungal identification was carried out by macroscopic observation of colony morphology and microscopic morphology with the aid of slide culture technique with lacto phenol cotton blue (LPCB) staining. Molecular identification of the fungus was based on the analysis of the Internal Transcribed Spacer (ITS) region sequence. Fungal genomic DNA was isolated [24]. The ITS region was PCR - amplified with universal primers, ITS1 (5' TCCGTAGGTGAACCTGCGG 3') and ITS4 (5' TCCT CCGCTTATTGATATGC 3') [25] using the following thermal profile; initial denaturation at $95^{\circ} \mathrm{C}$ for $10 \mathrm{~min}$, 30 cycles of denaturation at $95^{\circ} \mathrm{C}$ for $1 \mathrm{~min}$, annealing at $55^{\circ} \mathrm{C}$ for $1 \mathrm{~min}$ and extension at $72^{\circ} \mathrm{C}$ for $90 \mathrm{~s}$ and a final extension at $72^{\circ} \mathrm{C}$ for $10 \mathrm{~min}$. Sequence analysis was as described above.

\section{Analysis of HXD biodegradation of co-cultures and individual counterparts by GC-MS}

Co-cultures and individual counterparts were assayed for HXD biodegradation. Erlenmeyer flasks $(100 \mathrm{~mL})$ containing $20 \mathrm{~mL}$ BH medium with $1 \% \mathrm{HXD}(7652.53 \mathrm{mg} / \mathrm{L})$ was inoculated $\left(5^{*} 10^{4}\right.$ bacterial cells $/ \mathrm{mL}, 5^{*} 10^{3}$ fungal spores $\left./ \mathrm{mL}\right)$ and incubated continuously for 14 days. Control flasks were incubated under identical conditions but devoid of the microbial inoculum (negative control).

At the end of 14 days of incubation, residual HXD in the growth medium was extracted four times with hexane $(5 \mathrm{~mL})$ and the combined solvent extract was dried using anhydrous sodium sulfate $\left(\mathrm{Na}_{2} \mathrm{SO}_{4}\right)$. HXD in hexane was then quantified chromatographically via Gas chromatography-Mass spectrometry (GC-MS) using Agilent 7890a GC system equipped with 5975c MS system, split injector, and a capillary column (Agilent 19,091 s-33HP-5MS 5\% Phenyl Methyl Silox; $30 \mathrm{~m} \times$ $250 \mu \mathrm{m} \times 0.25 \mu \mathrm{m})$. The optimized temperature program was as follows; oven temperature $50^{\circ} \mathrm{C}$ for 5 min, then increased to $250^{\circ} \mathrm{C}$ at a rate of $20^{\circ} \mathrm{C} / \mathrm{min}$ and kept at $250^{\circ} \mathrm{C}$ for $1 \mathrm{~min}$ where the total run time was $16 \mathrm{~min}$. The injector temperature was maintained at $270{ }^{\circ} \mathrm{C}$. The carrier gas used in the column was helium at a flow rate of $1.5 \mathrm{~mL} / \mathrm{min}$ [26]. Chromatographic peak for HXD was obtained at the retention time of $12.66 \mathrm{~min}$. 
The chromatogram obtained by GC-MS analysis showed the relative abundance of HXD in the hexane extract. The biotic degradation of the HXD was obtained from the difference in the area of HXD peak of the sample and the control, and percentage degradation was calculated.

\section{Scanning Electron microscopic (SEM) observation of C1}

The scrap of the mature biofilm (after 14 days) was transferred onto an EM stub and allowed to air dry (approx. $30 \mathrm{~min}$ ). The sample was examined under a scanning electron microscope (TESCAN VEGA3).

\section{Degradation of other hydrocarbons}

Erlenmeyer flasks $(100 \mathrm{~mL})$ containing $20 \mathrm{~mL} \quad \mathrm{BH}$ medium supplemented with $1 \%$ of filter-sterilized crude oil, diesel or petrol as the sole carbon source respectively, were inoculated with $\mathrm{C} 1$ community and incubated continuously for 14 days $\left(40^{\circ} \mathrm{C}\right.$ without agitation). Crude oil degradation was observed visually. Degradation of petrol and diesel was detected using Dichlorophenolindophenol (DCPIP). Filter sterilized DCPIP solution was added to the medium to detect the utilization of the carbon source by the color change of the medium, from bright blue to colorless [27].

\section{Statistical analysis}

One-way ANOVA and multiple comparisons of means by using Tukey's HSD test in the SPSS v.18.0 (SPSS Inc.; IBM Company; Chicago, IL, USA) statistical package were applied to determine the statistical significance (at $p<0.05$ ) of the percentage degradation of HXD by the three communities. All data are presented as means \pm standard deviation of triplicates $(n=3)$.

\section{Results}

\section{Culture enrichment and isolation of microbes}

A mixed community of bacteria was obtained from samples (waste polythene attached with soil) collected from the municipal landfill. Ten well separated bacterial colonies were isolated and preserved.

\section{Screening and selection of isolates}

Ten bacterial isolates were grown in 1\% HXD in planktonic mode, where the turbidity was observed throughout the culture medium. Among the ten bacterial isolates, three were subsequently observed to form mixed communities with fungi, where mycelial growth was observed on the liquid medium, shifting the community structure towards the biofilm mode, reducing the turbidity of planktonic bacterial cells in the medium. Further, this development was concomitant with the disintegration of the HXD layer resulting in formation of noticeable oil droplets, compared to the rest of the isolates. Therefore, these three mixed communities $(\mathrm{C} 1, \mathrm{C} 2, \mathrm{C} 3)$ were selected for further study.

\section{Isolation of community counterparts}

The three bacteria associated with each community had similar colony characteristics. Macroscopic identification of the fungal component in each community revealed that while $\mathrm{C} 1$ and $\mathrm{C} 2$ bacterial isolates were associated with a single fungus, C3 comprised of three fungi along with its bacterium.

\section{Identification of microbes in the selected community}

Grams staining and biochemical characterization identified the bacterium in C1 as a Gram's positive, active motile, endospore forming, rod shaped facultative anaerobe (Table 1).

BLAST analysis of the nucleotide sequence of $16 \mathrm{~s}$ rRNA gene of the bacterium showed the maximum identity with $B$. cereus group bacteria, B. cereus, B. thuringiensis and $B$. anthracis, revealing that it is difficult to differentiate between them [28-31]. B. anthracis is non-motile. Since, bacterium in $\mathrm{C} 1$ community of our study is an active motile strain (Table 1) it was concluded to be a $B$. cereus/B. thuringiensis (Bacillus sp. MM1; GenBank accession no. MH503924).

The fungus in $\mathrm{C} 1$ grown on SDA plates for 3 to 5 days exhibited morphological features as follows; white velvety colonies with floccose texture changed during sporulation in to a greenish-gray with white edges on the anverse side and light brown on the reverse side. Slide cultures of the fungal isolate were prepared on SDA medium by growing for 3 to 5 days, for microscopic observation. BLAST analysis of the nucleotide sequence of the $416 \mathrm{bp}$ fragment of ITS region revealed the fungus belongs to the genus Aspergillus sp. (Aspergillus sp. MM1; GenBank accession no. MH503926). Further, $100 \%$ homology was found with A. flavus complex fungi, $A$. flavus and $A$. oryzae sequences, reported in GenBank (NCBI). Species differentiation of the fungus of the $\mathrm{C} 1$ community between $A$. flavus and $A$. oryzae has also been shown to be controversial [30, 31].

\section{HXD biodegradation of co-cultures and individual counterparts by GC-MS}

Utilization of HXD as sole carbon source by $\mathrm{C} 1, \mathrm{C} 2$ and C3 communities were compared by GC-MS analysis of residual HXD. HXD biodegradation by the three co-cultures C1, C2 and C3 after 14 days incubation were $99.42 \pm$ $0.38 \%, 79.4 \pm 1.65 \%$ and $98.74 \pm 0.23 \%$ respectively (Fig. 1 ) and difference between three communities were statistically significant (one-way ANOVA; $P<0.001$ ). The HXD degradation capability of the $\mathrm{C} 1$ and $\mathrm{C} 3$ communities were both significantly higher than $\mathrm{C} 2(P=0.021$ and $P=0.025$ respectively). $\mathrm{C} 1$ and $\mathrm{C} 3$ communities revealed the highest degradation activity, with no significant difference between them $(P<0.05)$. However, $\mathrm{C} 1$ comprised of a single bacterium and a single fungus while $\mathrm{C} 3$ showed the involvement 
Table 1 Biochemical characterization of the bacterium in C1, C2, and C3

\begin{tabular}{|c|c|c|c|}
\hline \multirow[b]{2}{*}{ Characteristics } & \multicolumn{3}{|c|}{ Bacterial isolates in the isolated communities } \\
\hline & C1- bacterium & C2- bacterium & C3- bacterium \\
\hline Gram's reaction & + & + & + \\
\hline Motility & Active motile & Non-motile & motile \\
\hline Endospores & + & + & + \\
\hline position & Sub terminal & Sub terminal & Sub terminal \\
\hline shape & Oval & Oval & Oval \\
\hline swollen/no swelling & Swollen & No swelling & No swelling \\
\hline Cell shape & Rods & Rods & Rods \\
\hline Oxygen relationship & Facultative anaerobe & Facultative anaerobe & Facultative anaerobe \\
\hline Catalase (aerobe) & + & + & + \\
\hline Oxidase (aerobe) & + & + & + \\
\hline Nitrate reduction (anaerobe) & + & + & + \\
\hline Voges-proskuer test & - & - & - \\
\hline \multicolumn{4}{|l|}{ Glucose fermentation } \\
\hline gas production & - & - & - \\
\hline acid production & + & + & + \\
\hline \multicolumn{4}{|l|}{ Fermentation of sugars } \\
\hline L- arabinose & - & - & + \\
\hline D-xylose & - & - & + \\
\hline D-mannitol & - & - & - \\
\hline D-mannose & - & + & - \\
\hline Casein hydrolysis & + & + & + \\
\hline Gelatin hydrolysis & + & + & + \\
\hline Starch hydrolysis & - & - & + \\
\hline Citrate utilization & + & + & + \\
\hline Tyrosine degradation & - & - & - \\
\hline Lecithinase activity & - & - & - \\
\hline Indole test & - & - & - \\
\hline \multicolumn{4}{|l|}{ Growth at pH } \\
\hline 6.8 & + & + & + \\
\hline 5.7 & - & - & - \\
\hline \multicolumn{4}{|l|}{ Growth in $\mathrm{NaCl}$} \\
\hline $7 \%$ & + & + & + \\
\hline $10 \%$ & + & + & + \\
\hline \multicolumn{4}{|l|}{ Growth at temperatures } \\
\hline $30^{\circ} \mathrm{C}$ & + & + & + \\
\hline
\end{tabular}

of at least three species of fungi interacting with a single bacterium, forming the community. Hence, $\mathrm{C} 1$ was selected for investigation, considering its efficiency and simplicity of the microbial composition.

Analysis of the activity of each of the interacting organisms in $\mathrm{C} 1$ under the same conditions showed that HXD biodegradation by the fungal and bacterial monocultures were $52.92 \pm 8.81 \%$ and $9.62 \pm 0.71 \%$ respectively, while the degradation by the co-culture was 99.42 $\pm 0.38 \%$. Thus, synergistic association between the fungus and the bacterium in the selected co-culture was evident (Fig. 1).

\section{Biofilm formation by the $\mathrm{C} 1$ community}

Light microscopic imaging of the mature community (after 14 days) grown on HXD showed visible colonization of the Bacillus cells on the Aspergillus mycelia. Scanning electron micrographs (SEM) further confirmed the formation of a 


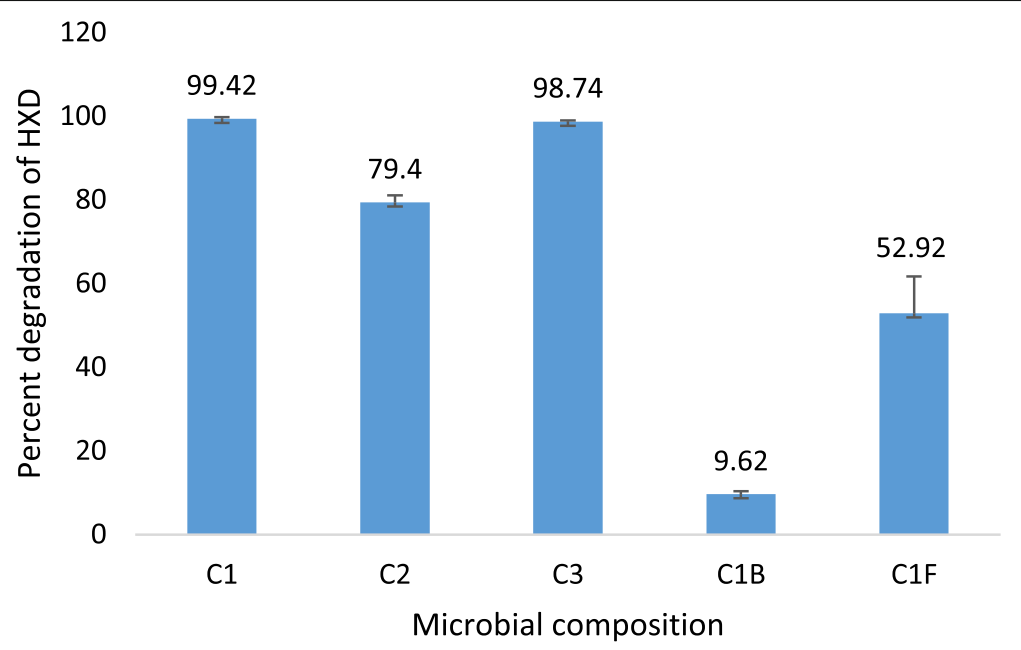

Fig. 1 Percentage degradation of HXD after 14 days by the three microbial communities (C1, C2, C3) and counterparts of C1 (C1B; Bacterium of C1, C1F; Fungus of C1). Error bars represent standard deviations $(n=3)$, Significance of mean differences was set at $P \geq 0.05$

biofilm by the Aspergillus - Bacillus community. It clearly shows the matrices of extracellular polymeric substances (EPS) which embedded the bacterial cells as well as the fungal mycelia in the mature biofilm (Fig. 2).

\section{Degradation of other hydrocarbons by the $\mathrm{C} 1$ community} Crude oil (1\%) as the sole carbon source in $\mathrm{BH}$ medium was visually observed to be utilized by $\mathrm{C} 1$ which showed the disintegration of the continuous oil layer (brown in color) in to oil droplets (Fig. 3). The DCPIP assay results confirmed the ability of $\mathrm{C} 1$ to utilize diesel as the sole carbon source $(1 \%)$ in the $\mathrm{BH}$ medium. But $1 \%$ petrol as sole carbon source in $\mathrm{BH}$ medium did not give a significant color change to DCPIP in the medium after 14 days, indicating that $\mathrm{C} 1$ is unable to utilize petrol.

\section{Discussion}

Mixed microbial communities such as those consisting of fungi and bacteria, can potentially provide an advantage for survival in an environment where both bioavailability and bio-accessibility of carbon sources are low. The symbiosis enables microbes to adapt to a new environment, survive in nutrient limiting conditions and further acquire metabolic alterations in order to thrive [32-35]. It also provides a potential for synergism.

In the present study, three natural fungal-bacterial communities which possess the ability to degrade hydrocarbons (under aerobic conditions) were isolated from Meethotamulla, a landfill in Colombo municipal area, Sri Lanka. Biodegradation of HXD in 14 days increased from $52.92 \pm 8.81 \%$ and $9.62 \pm 0.71 \%$ in the fungal and bacterial monocultures respectively, to
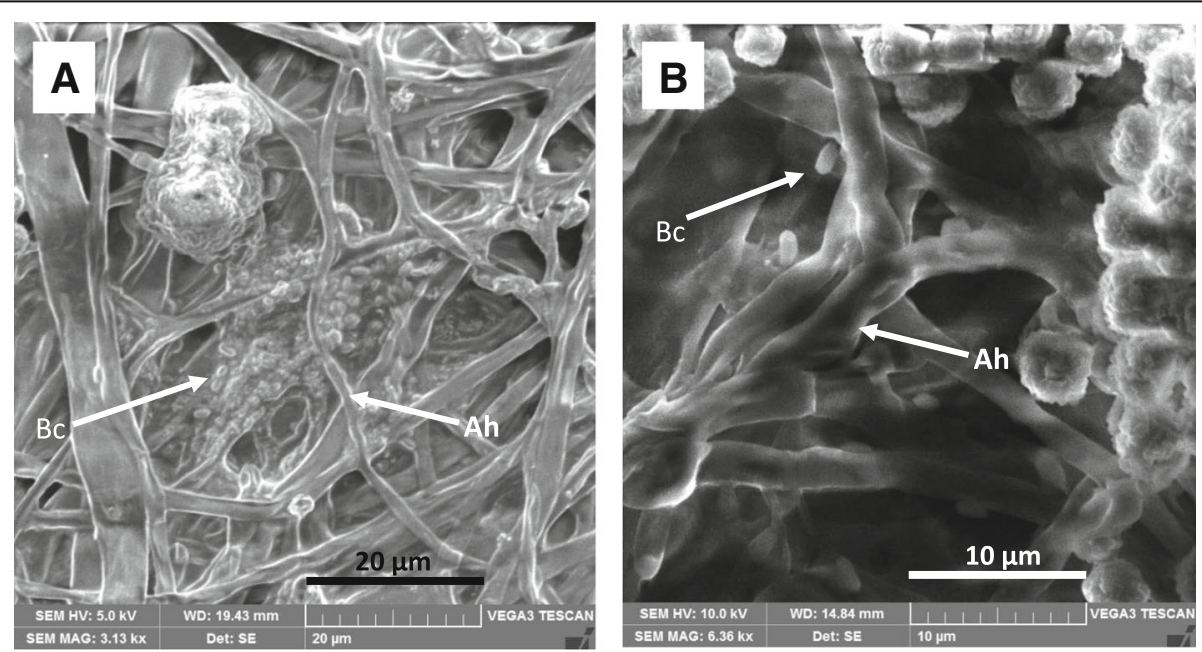

Fig. 2 SEM micrographs of mature Aspergillus - Bacillus biofilm (14 days after co-inoculation) formed in HXD containing medium. a Magnification 3130X b magnification 6360X; the arrows point either Aspergillus hyphae (Ah) or Bacillus cells (BC) 


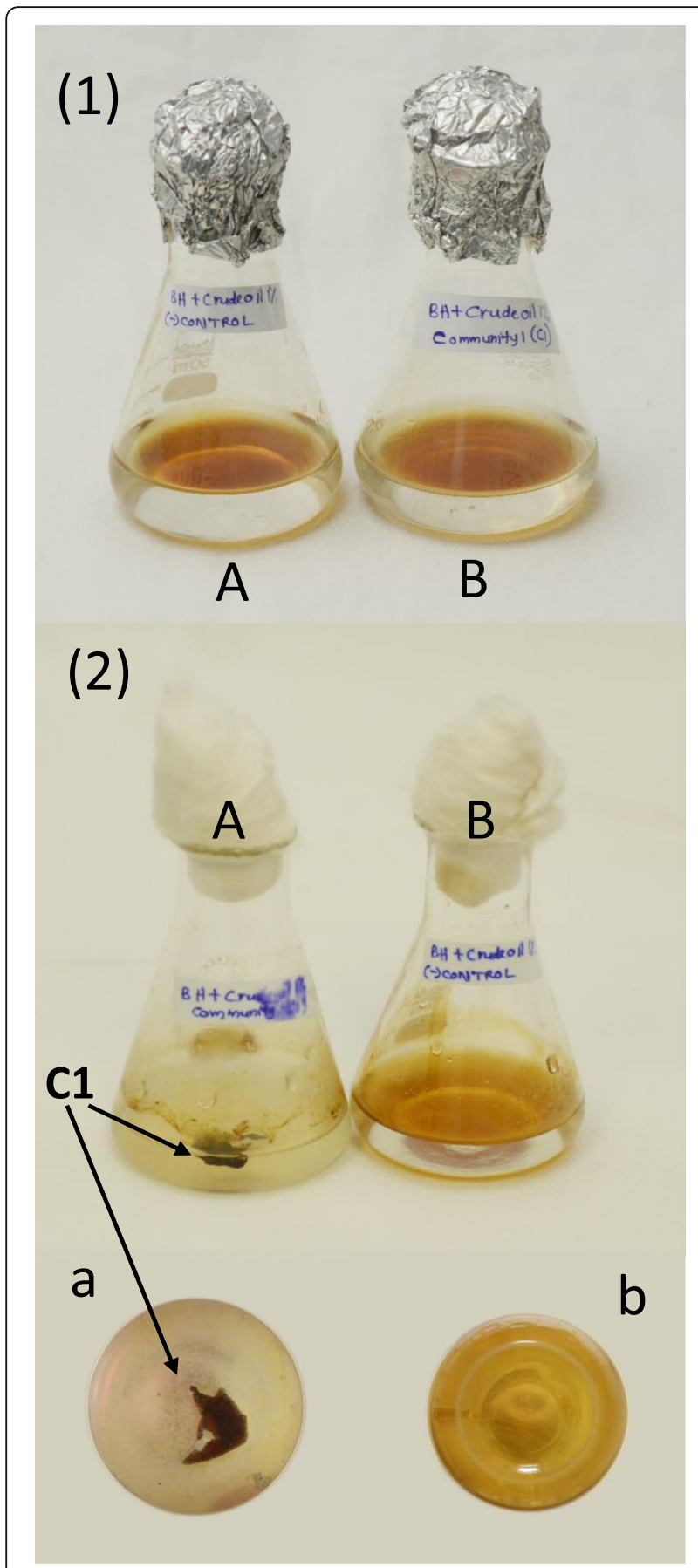

Fig. 3 Crude oil degradation by Aspergillus - Bacillus (C1) co-culture. (1) $1 \%$ crude oil in $\mathrm{BH}$ medium before incubation (A) negative control, (B) inoculated with C1 co-culture (2) $1 \%$ crude oil in BH medium after 14 days incubation (A) inoculated with C1 co-culture, (B) negative control (a), (b) A and B flasks after 14 days as viewed from bottom

$99.42 \pm 0.38 \%$ when in co-culture. This clearly demonstrated synergistic degradation of HXD as the sole carbon source by this naturally occurring $\mathrm{C} 1$ community in liquid medium.
C1 contains a bacterium from $B$. cereus group and a fungus from $A$. flavus complex. Several mixed microbial communities have been recorded in hydrocarbon degradation, such as Mycobacterium hyalinum and Cladosporium degrading diesel oil [34] and biodegradation of oil contaminated soil by a yeast - bacterial co-culture [35]. Degradation of 2-naphthol has been achieved by coupling A. niger with B. subtilis [36]. However, B. cereus group bacteria and $A$. flavus complex fungi have not been previously shown to act in a synergistic manner. Instead, $B$. cereus has been recorded for its use as a biocontrol agent of $A$. flavus due to their antagonistic behaviour [37].

Filamentous fungi are capable of producing hydrophobic proteins, enabling them to attach on to hydrophobic surfaces [38]. The fungal counterpart in the $\mathrm{C} 1 \mathrm{commu}-$ nity was observed to form its mycelial mat at the hydrophobic - hydrophilic interface in the HXD - BH medium. This allows the bacteria to overcome the nutrient limitation in submerged growth by attaching on to the fungal mycelium and gaining access to the hydrocarbon layer. The bacterium of $\mathrm{C} 1$ is an active motile strain (Table 1) and would thus be capable of travelling through the medium up to the fungal mat. Bacterial flagella motility is recorded to influence the movement towards a target surface and attachment to it $[15,16]$.

In the present study, proved synergistic association between the fungus and the bacterium of the $\mathrm{C} 1$ co-culture, leads to a hypothesis of a possible biofilm mode for the community structure. Previous studies have provided evidence for successful association of microbial communities consisting of more than one species, overcoming the need for an abiotic surface for the biofilm formation [2, 9, 39, 40].

Scanning electron microscopic images of the $\mathrm{C} 1 \mathrm{com}-$ munity (Fig. 2) confirmed the presence of the biofilm formation of the community interaction where Aspergillus hyphae is colonized by Bacillus cells and both embedded in an EPS matrix. Further, the bacterium of $\mathrm{C} 1$ being a facultative anaerobe as shown by biochemical analysis (Table 1), explains its ability to go in to a biofilm mode from its planktonic mode.

Genes coding for enzymes involved in aerobic respiration in B. subtilis are down-regulated upon its attachment to $A$. niger hyphae, allowing the bacterial metabolism to be shifted from aerobic to anaerobic [10]. This supports the idea of planktonic bacterial cells going in to the biofilm mode, attaching to hyphae and further being embedded in the EPS matrices, thus being exposed to an anaerobic environment.

Further, the $\mathrm{C} 1$ community in biofilm mode demonstrated the ability to utilize crude oil and diesel (which contains cetane/hexadecane and iso-cetane). Crude oil consists of a variety of chemically distinct hydrocarbons, 
including paraffins (alkanes), naphthenes (cycloalkanes), and aromatics (benzene, toluene, ethyl benzene, xylene etc.) which require specific mechanisms for activation and biodegradation [41]. Accordingly our Aspergillus Bacillus co-culture might be utilizing higher carbon number alkanes and also cycloalkanes and aromatic fraction of the crude oil, which needs further investigation.

Metabolic co-dependence in biofilm cells leads to halt the biofilm growth periodically and this is known as collective oscillation in biofilm growth. This benefits the community in nutrient limiting conditions [42]. The bacterium in the $\mathrm{C} 1$ community was shown to form endospores (Table 1). This would enable it to survive in a dormant state under nutrient limiting conditions. Since fungal spore produced for dissemination are also adapted for survival, both organisms are able to survive under prolonged stress conditions, allowing this combination to be used as a successful environmental remediation agent.

\section{Conclusion}

In conclusion, it is evident that there are naturally formed microbial communities which can efficiently degrade hydrocarbons under aerobic conditions. Their degradation capacity of crude oil and diesel is higher than that of mono cultures of their counterparts, demonstrating the synergistic behavior in biofilm mode. The study suggests that the density of such communities in the nature is too low to have a significant effect on the hydrocarbon removal from contaminated sites. Thus, isolation, multiplication and utilization of the naturally occurring communities may provide a more superior option than induced communities for bioremediation purposes.

\section{Additional files}

Additional file 1: Chromatograms_GCMS 1. Chromatograms for residual HXD analyzed by GC-MS after 14 day incubation of cultures of the three communities (C1,C2 \& C3) and counterparts of community C1. (PDF $828 \mathrm{~kb}$ )

Additional file 2: Chromatograms_GCMS 2. Balance chromatograms for residual HXD analyzed by GC-MS after 14 day incubation of cultures of the three communities $(C 1, C 2 \&$ C 3$)$ and counterparts of community $C 1$. (PDF $132 \mathrm{~kb}$ )

Additional file 3: Key to chromatograms in Additional files 1 and 2 . (DOCX $12 \mathrm{~kb}$ )

\section{Abbreviations}

BH: Bushnell and Haas; BLAST: Basic Local Alignment Search Tool; CEYPETCO: Ceylon Petroleum Corporation;

DCPIP: Dichlorophenolindophenol; EPS: Extracellular polymeric substances; GC-MS: Gas Chromatography-Mass Spectrometry; HXD: Hexadecane; ITS: Internal Transcribed Spacer; LPCB: Lacto phenol cotton blue; NA: Nutrient agar; NB: Nutrient broth; NCBI: National Center for Biotechnology Information; PCR: Polymerase chain reaction; SDA: Sabouraud dextrose agar; SDB: Sabouraud dextrose broth; SEM: Scanning Electron Microscopy

\section{Acknowledgments}

We thank Mr. Keerthi Wickramarathne, Medical Research Institute (MRI), Sri Lanka for technical assistance with SEM imaging.
Funding

This work was funded by the research grant AP/3/2/2014/RG/12, University of Colombo.

\section{Availability of data and materials}

The Sequence data have been deposited in the GenBank, http://www.ncbi. nlm.nih.gov/nuccore/MH503924 \& http://www.ncbi.nlm.nih.gov/nuccore/ MH503926. Accession numbers are indicated in the text. The chromatograms supporting the conclusions of this article are included as Additional files 1,2 and 3. Other datasets generated during and/or analyzed during the current study are available from the corresponding author on reasonable request.

\section{Authors' contributions}

SJ and SW conceptualized and designed the study. MP carried out all the experimental work, interpreted the data and wrote the manuscript. MC supervised the GC-MS analysis. DW, GS contributed to study design and data interpretation. All authors contributed to manuscript preparation, editing and approved the final version.

Ethics approval and consent to participate

Not applicable.

Consent for publication

Not applicable.

Competing interests

The authors declare that they have no competing interests.

\section{Publisher's Note}

Springer Nature remains neutral with regard to jurisdictional claims in published maps and institutional affiliations.

\section{Author details}

'Department of Biochemistry and Molecular Biology, Faculty of Medicine, University of Colombo, Colombo 08, Sri Lanka. ${ }^{2}$ Department of Chemistry, Faculty of Science, University of Colombo, Colombo, Sri Lanka. ${ }^{3}$ Department of Chemistry, Faculty of Applied Sciences, University of Sri Jayewardenepura, Nugegoda, Sri Lanka. ${ }^{4}$ National Institute of Fundamental Studies, Hantana Road, Kandy, Sri Lanka.

Received: 29 August 2018 Accepted: 17 April 2019 Published online: 29 April 2019

\section{References}

1. Van Hamme JD, Singh A, Ward OP. Recent advances in petroleum microbiology. Microbiol Mol Biol Rev. 2003;67(4):503-49.

2. Singh R, Paul D, Jain RK. Biofilms: implications in bioremediation. Trends Microbiol. 2006;14(9):389-97.

3. Davey ME, Toole GAO. Microbial biofilms : from ecology to molecular genetics. Microbiol Mol Biol Rev. 2000;64(4):847-67.

4. Hays SG, Patrick WG, Ziesack M, Oxman N, Silver PA. Better together: engineering and application of microbial symbioses. Curr Opin Biotechnol [Internet] 2015;36:40-49. Available from: https://doi.org/10.1016/j.copbio. 2015.08 .008

5. Seneviratne G, Zavahir JS, Bandara WMMS, Weerasekara MLMAW. Fungalbacterial biofilms: their development for novel biotechnological applications. World J Microbiol Biotechnol. 2008;24(6):739-43.

6. Dörr J, Hurek T, Reinhold-Hurek B. Type IV Pili are involved in plant microbe and fungus - microbe interactions. Mol Microbiol [internet]. 1998; 30(1):7-17. Available from: http://www.ncbi.nlm.nih.gov/pubmed/9786181.

7. Wick LY, Remer R, Wurz B, Reichenbach J. Sebastian, Braun Franziska S, harms $\mathrm{H}$. effect of fungal hyphae on the access of bacteria to phenanthrene in soil. Environ Sci Technol. 2007;41(2):500-5.

8. Arora DK, Gupta S. Effect of different environmental conditions on bacterial chemotaxis toward fungal spores. Can J Microbiol. 1993;39:922-31.

9. Hogan D, Hogan DA, Wargo MJ, Beck N. Bacterial biofilms on fungal surfaces. 2009:(May 2016).

10. Benoit I, van den Esker MH, Patyshakuliyeva A, Mattern DJ, Blei F, Zhou M. Bacillus subtilis attachment to Aspergillus niger hyphae results in mutually altered metabolism. Environ Microbiol. 2015;17(6):2099-113. 
11. Lee SW, Cooksey DA. Genes expressed in Pseudomonas putida during colonization of a plant-pathogenic fungus. Appl Environ Microbiol. 2000;66:2764-72.

12. Gaballa A, Abeysinghe PD, Urich G, Matthijs S, De Greve H, Cornelis P, et al. Trehalose induces antagonism towards Pythium debaryanum in Pseudomonas fluorescens ATCC 17400. Appl Environ Microbiol. 1997:63(11):4340-5.

13. De WS, Dekkers LC, Kuiper I, Bloemberg GV, BJJ L. Role of chemotaxis toward fusaric acid in colonization of hyphae of generation of enhanced competitive Root-Tip-Colonizing Pseudomonas Bacteria through Accelerated Evolution. J Bacteriol. 2014;186:3153-9.

14. Vu B, Chen M, Crawford RJ, Ivanova EP. Bacterial extracellular polysaccharides involved in biofilm formation. Molecules. 2009:2535-54.

15. Kirov SM, Castrisios M, Shaw JG. Aeromonas Flagella (polar and lateral) are enterocyte adhesins that contribute to biofilm formation on surfaces. Infect Immun. 2004;72(4):1939-45.

16. Vatanyoopaisarn S, Nazli A, Dodd CER, Rees CED, Waites WM. Effect of flagella on initial attachment of Listeria monocytogenes to stainless steel. Appl Environ Microbiol. 2000;66(2):860-3.

17. Ramarao N, Lereclus D. Adhesion and cytotoxicity of Bacillus cereus and Bacillus thuringiensis to epithelial cells are FlhA and PIcR dependent, respectively. Microbes Infect. 2006;8(6):1483-91.

18. Dar GH. Soil microbiology and biochemistry. In Delhi: New india publishing agency; 2010. p. 70-1. Available from: https://books.google.lk/books?id= PVOInpQ3k34C\&pg=PA91\&lpg=PA91\&dq=Ghulam+hassan+Dar+Soil +Microbiology+and+Biochemistry++depth+of+soil+aerobic +bacteria\&source=bl\&ots=i47Q5K4_7F\&sig=vSEvGoBpGrnCUa080l8MgCdfaY\&hl=en\&sa=X\&ved= OahUKEwj6tuut6OHbAhXMLo8KHWORAWg.

19. Bushnell LD, Haas HF. Th e utilization of certain hydrocarbons by microorganisms. J Bacteriol. 1940:41:653-73.

20. Zimbro MJ, Power DA. Difco \& BBL manual : manual of microbiological culture media. Parks, MD: Difco Laboratories, Division of Becton Dickinson and Co; 2003.

21. Sambrook, J., Fritsch, E. F., and Maniatis T. No title. 2nd ed. Molecular Cloning: A LABORATORY MANUAL. Cold SpringHharbor Laboratary Press; 1989.

22. Krieg NR, Holt JG. Bergey's manual of systematic bacteriology, vol. 1. Baltimore: Williams and Wilkins Co.; 1984. p. 161-72.

23. Lane DJ. 16S/23S rRNA sequencing. In: E S, M G, editors. New York, N.Y. John Wiley and Sons, Inc.; 1991. p. 115-176.

24. Lee SB, Taylor JW. Isolation of DNA from fungal mycelia and single spores. In: PCR PROTOCOLS: A GUIDE TO METHODS AND APPLICATIONS [Internet] Academic Press, Inc.; 1989. p. 282-7. Available from: https://doi.org/10.1016/ B978-0-12-372180-8.50038-X

25. White TJ, Bruns T, Lee S, Taylor J. Amplification and direct sequencing of fungal ribosomal rna genes for phylogenetics. PCR Protocols. 1990:315-22. Available from: http://linkinghub.elsevier.com/retrieve/pii/ B9780123721808500421.

26. Liu T, Wang F, Guo L, Li X, Yang X, Lin AJ. Biodegradation of n-hexadecane by bacterial strains B1 and B2 isolated from petroleum-contaminated soil. Sci China Chem. 2012;55(9):1968-75.

27. Hanson KG, Desai JD, Desai AJ. A rapid and simple screening technique for potential crude oil degrading microorganisms. Biotechnol Tech. 1993;7(10):745-8

28. Zahner V, de Carvalho e Silva ACT, de Moraes GP, McIntosh D, de Filippis I. Extended genetic analysis of Brazilian isolates of Bacillus cereus and Bacillus thuringiensis. Mem Inst Oswaldo Cruz. 2013;108(1):65-72.

29. Liu Y, Lai Q, Göker M, Meier-Kolthoff JP, Wang M, Sun Y, et al. Genomic insights into the taxonomic status of the Bacillus cereus group. Sci Rep 2015; 5:1-11. Available from: https://doi.org/10.1038/srep14082

30. Payne GA, Nierman WC, Wortman JR, Pritchard BL, Brown D, Dean RA, et al. Whole genome comparison of Aspergillus flavus and A. oryzae. Med Mycol. 2006:44(SUPPL. 1):9-11.

31. Rank C, Klejnstrup ML, Petersen LM, Kildgaard S, Frisvad JC, Held Gotfredsen C, et al. Comparative chemistry of Aspergillus oryzae (RIB40) and A. flavus (NRRL 3357). Metabolites [Internet]. 2012;2(4):39-56. Available from: http:// www.mdpi.com/2218-1989/2/1/39/

32. Kwon KK, Lee HS, Jung S, Yim J, Lee J, Lee HK. Isolation and identification of biofilm-forming marine bacteria on glass surfaces in Dae-ho dike. Korea J Microbiol. 2002;40(4):260-6.

33. Folwell BD, MCGenity TJ, Whitby C. Characterisation of biofilm and planktonic bacterial and fungal communities transforming high molecular weight polycyclic aromatic hydrocarbons. Appl Environ Microbiol. 2016; 82(8):AEM.03713-5. Available from: http://aem.asm.org/lookup/doi/10.1128/ AEM.03713-15.

34. Li YQ, Liu HF, Le Tian Z, Zhu LH, Wu YH, Tang HQ. Diesel pollution biodegradation: synergetic effect of Mycobacterium and filamentous fungi. Biomed Environ Sci. 2008;21(3):181-7.

35. Zhang C, Qi J, Cao Y. Synergistic effect of yeast-bacterial co-culture on bioremediation of oil-contaminated soil. Bioremediat J. 2014;18(2):136-46.

36. Zang S, Lian B, Wang J, Yang Y. Biodegradation of 2-naphthol and its metabolites by coupling Aspergillus niger with Bacillus subtilis. J Environ Sci [Internet]. 2010;22(5):669-74. Available from: https://doi.org/10.1016/S10010742(09)60161-3.

37. Kumar SN, Sreekala SR, Chandrasekaran D, Nambisan B, Anto RJ. Biocontrol of Aspergillus species on peanut kernels by antifungal diketopiperazine producing Bacillus cereus associated with entomopathogenic nematode. PLoS One. 2014;9(8):e106041.

38. Kershaw MJ, Talbot NJ. Hydrophobins and repellents: proteins with fundamental roles in fungal morphogenesis. Fungal Genet Biol. 1998;23(1):18-33.

39. Senevirate G, Tennakoon NS, Weerasekara M, Nandasena KA. Polythene biodegradation by a developed Penicillium-Bacillus bofilm. Curr Sci. 2006;90:20-1.

40. Buddhika UVA, Seneviratne G, Abayasekara CL. Fungal-bacterial biofilms differ from bacterial monocultures in seed germination and indole acetic acid production. Int J Sci Res Publ. 2014;4(1):1-5.

41. McGenity TJ, Folwell BD, BA MK, Sanni GO. Marine crude-oil biodegradation: a central role for interspecies interactions. Aquat Biosyst. 2012;8(1):10 Available from: Saline Systems.

42. Liu J, Prindle A, Humphries J, Gabalda-sagarra M, Asally M, Lee DD. Metabolic co-dependence gives rise to collective oscillations within biofilms. Nature. 2015:1-5.

\section{Ready to submit your research? Choose BMC and benefit from:}

- fast, convenient online submission

- thorough peer review by experienced researchers in your field

- rapid publication on acceptance

- support for research data, including large and complex data types

- gold Open Access which fosters wider collaboration and increased citations

- maximum visibility for your research: over $100 \mathrm{M}$ website views per year

At $\mathrm{BMC}$, research is always in progress.

Learn more biomedcentral.com/submissions 